\title{
The effect of alendronate sodium on trabecular bone structure in an osteoporotic rat model
}

\author{
Esin Tokmak Özşahin, ${ }^{1}$ Burcu Çam, ${ }^{2}$ Fahri Dere, ${ }^{3}$ Mehmet Kürkçü, ${ }^{2}$ Cüneyt Evrüke, ${ }^{4}$ Roger Soames, ${ }^{5}$ Özkan Oğuz ${ }^{3}$ \\ ${ }^{1}$ Department of Anatomy, Başkent University Adana Hospital, Adana, Turkey \\ 2Department of Maxillofacial and Oral Surgery, Çukurova University School of Dentistry, Adana, Turkey \\ ${ }^{3}$ Department of Anatomy, Medical Faculty of Çukurova University, Adana, Turkey \\ ${ }^{4}$ Department of Obstetrics and Gynecology, Medical Faculty of Çukurova University, Adana, Turkey \\ ${ }^{5}$ Dundee University, Center for Anatomy, Dundee, England \\ Received: January 2016 Accepted: May 2016
}

\section{ABSTRACT}

Objectives: This study aims to investigate the effect of alendronate sodium on trabecular bone structure in an osteoporotic rat model.

Materials and methods: Between May 2006 and July 2006, 60 female Wistar Albino rats aged three months were randomly allocated to three groups: sham operated receiving no treatment ( $\mathrm{Shm})$; ovariectomized-alendronate receiving $1 \mathrm{mg} / \mathrm{kg} /$ day alendronate sodium $(\mathrm{Ovx}-\mathrm{A})$, and ovariectomized-vehicle receiving $1 \mathrm{~mL} / \mathrm{kg}$ /day physiological saline (Ovx-PS). Both Ovx groups received treatment through gastric gavage for 56 days.

Results: Densitometric measurements showed that bone mineral density decreased in the Ovx-PS and increased in Ovx-A groups ( $\mathrm{p}<0.05)$. Biomechanical measurements showed a decrease in the breaking force in the Ovx-PS group and an increase in the Ovx-A group (p<0.05). Histomorphometric measurements showed that the Shm group had normal trabecular structure, while the Ovx-PS group had a less wellformed trabecular structure with a loss in the trabecular number and thickness and a corresponding increase in the trabecular spacing $(\mathrm{p}<0.05)$. In the Ovx-A group, there was an improvement in the trabecular structure with an increase in the trabecular number and thickness and a loss in the trabecular space $(\mathrm{p}<0.05)$.

Conclusion: Our study results suggest that alendronate sodium is a valuable treatment agent for osteoporosis in postmenopausal women.

Keywords: Alendronate sodium; biomechanics; densitometry; histomorphometry; osteoporosis.

Osteoporosis is a multi-factorial systemic disease characterized by increased bone fragility resulting from deterioration of the micro-architecture of the bone. The condition results in increased mortality and morbidity, particularly in postmenopausal women who suffer from hip and vertebral fractures. ${ }^{[1-3]}$

Currently, the most effective agents for the treatment of postmenopausal osteoporosis are bisphosphonates which are the structural analogues of inorganic pyrophosphates showing a selective activity on bone by having potent chemical affinities to hydroxyapatite, the main organic component of the bone. The use of alendronate sodium has been shown to increase bone mineral density and decrease fractures, particularly in vertebrae and hip, in osteoporotic patients. Several studies in ovariectomized (Ovx) rats have shown that alendronate sodium has a clinical effect for the treatment and protection of postmenopausal osteoporosis, by increasing the bone mass and mechanical strength. ${ }^{[3]}$

The most commonly used agents for osteoporosis are alendronate and risedronate: alendronate is more potent and selective, compared to other bisphosphonates, owing to its side chain of an amino acid group. ${ }^{[4]}$

To date, several animal models have been used to study the bone loss. The Ovx rat model is the most common model which is accepted by the United States Food and Drug Administration (FDA) as the 
most appropriate model to show postmenopausal bone loss. ${ }^{[5,6]}$

In the present study, we aimed to investigate the effect of alendronate sodium on the bone trabecular structure using densitometric, biochemical, and biomechanical analyses.

\section{MATERIALS AND METHODS}

Between May 2006 and July 2006, a total of 60-3 month old female Wistar Albino rats were obtained from Çukurova University Medical Research Center (TIBDAM). All animals received a pelleted standard chow diet containing $1 \%$ calcium, $0.7 \%$ phosphorus, $1000 \mathrm{IU} / \mathrm{kg}$ Vitamin D3, and $300 \mathrm{IU} / \mathrm{kg}$ Vitamin A (Tavaş Yem Sanayi ve Ticaret AŞ, Adana, Turkey). The rats were housed under local vivarium conditions (temperature $23 \pm 2{ }^{\circ} \mathrm{C}$, humidity $55 \pm 10 \%$, 12-h light-dark cycle) with access to water and chow diet ad libitum. Animal procedures were approved by the Çukurova University Ethics Committee and performed in compliance with the guidelines of Çukurova University, Medical Research Center for the care and handling of experimental animals.

The rats were randomly allocated to the following groups: sham-operated control group (Shm: $n=20$ ); Ovx group receiving physiological saline (Ovx-PS: $\mathrm{n}=20$ ); and Ovx group receiving alendronate sodium (Ovx-A: $\mathrm{n}=20$ ).

Surgery was undertaken under general anesthesia: $20 \mathrm{mg} / \mathrm{kg}$ Xylazine $\mathrm{HCl}$ intraperitoneally (Rompun, Bayer Türk Kimya San Ltd., İstanbul, Turkey) and $1 \mathrm{mg} / \mathrm{kg}$ ketamin (Alfamyne ${ }^{\oplus}$, Egevet, Izmir, Turkey). In all groups, the abdomen was opened and, then, closed with the dermis and epidermis being primarily sutured. Bilateral ovariectomy was performed in the Ovx-PS and Ovx-A groups. Following operation, the rats were allowed to recover for seven days. The Ovx-A group was given $1 \mathrm{mg} / \mathrm{kg} /$ day alendronate sodium (Osalen, Eczacıbaşı, İstanbul, Turkey), while the Ovx-PS group received $1 \mathrm{~mL} / \mathrm{kg} /$ day physiological saline, both through gastric gavage for 56 days. All animals were sacrificed on Day 57 by decapitation following intraperitoneally $10 \mathrm{mg} / \mathrm{kg}$ Xylazine $\mathrm{HCl}$.

Five animals were randomly selected from each group for biochemical assessment and kept in metabolic cages prior to sacrifice. Twenty-four hour urine samples were obtained to measure urinary creatinine and calcium levels: blood samples were obtained from the abdominal aorta via an heparinized syringe from which plasma calcium, creatinine, and osteocalcin levels were measured.
The femurs, tibiae, and L1 and L2 vertebrae were removed from each animal after sacrifice and placed in $10 \%$ formaldehyde solution until analyzed in the Hard Tissue Laboratory, Department of Dentistry of Cukurova University.

The maximum diameters of the proximal tibial condyles and of the proximal tibial shafts were measured using digital calipers with corrected data.

Densitometric assessment was performed on the tibia and L1 and L2 with two measurements being made on each bone. The samples were placed on a digital sensor: an aluminum guide was used in all samples to provide calibration and standardization. The procedure was conducted using $65 \mathrm{Kvp}$, $7.5 \mathrm{~mA} x$ light source (Gendex, Oralix, Milano, Italy). The digital images which were obtained were converted into TIF format and analyzed using the Bioquant Osteo II software (Nashville, Tennessee USA).

Ten tibiae from each group were used for mechanical testing. Each sample was prepared for three-point bending test in a Testometric AX M500 25kN machine (Testometric Co. Rochdale, UK). The breaking forces were recorded.

Undecalcified bone preparations and bone histomorphometry were undertaken in the Hard Tissue Laboratory of Cukurova University. The femurs, tibiae, and vertebrae samples were placed in $10 \%$ buffered formalin at room temperature for at least for 24 hours and were primarily fixed with formaldehyde solution at $4{ }^{\circ} \mathrm{C}$ for $15-30 \mathrm{~min}$. Dehydration was by immersion in increasing alcohol baths (70 to $99 \%$ ). The samples were mixed with pure glycol methyl ether acrylate and an embedding material (embedding medium, Technovit 7200 VLC) at $1: 1$ ratio and were kept in liquid for 8 to 12 hours under vacuum.

The samples were, then, embedded in specially designed transparent boxes under vacuum to prevent formation of air bubbles. The boxes were polymerized at $40^{\circ} \mathrm{C}$ under yellow light for four hours. Once penetration into the tissue was complete, the embedding material was fully polymerized under the blue light. The hardened blocks were, then, removed from the transparent boxes and $10 \mu \mathrm{m}$ undecalcified sections prepared using EXAKT sensitive cutting and erosion units (EXAKT Apparatebau GmbH \& Co KG, Norderstedt, Germany). The resulting sections were stained with $1 \%$ toluidine blue.

The preparations were assessed using an Olympus BX50 microscope (Olympus ${ }^{\oplus}$ BX50, Tokyo, Japan). Digital images at $40 \mathrm{x}$ magnification were obtained from the sections using a digital camera mounted 
Table 1. Means and standard deviations of plasma osteocalcin, creatinine, and calcium and of the urine creatinine and calcium values according to experimental groups

\begin{tabular}{|c|c|c|c|}
\hline & Shm & Ovx-PS & Ovx-A \\
\hline & $\overline{\text { Mean } \pm \text { SD }}$ & Mean \pm SD & Mean \pm SD \\
\hline \multicolumn{4}{|l|}{ Plasma } \\
\hline Osteocalcin (mg/dL) & $17.4 \pm 3.1$ & $2.2 \pm 2.6^{*}$ & $16.9 \pm 5.7$ \\
\hline Creatinine $(\mathrm{mg} / \mathrm{dL})$ & $0.5 \pm 0.1$ & $0.6 \pm 0.2$ & $0.4 \pm 0.0$ \\
\hline Calcium (mg/dL) & $9.6 \pm 0.3$ & $7.5 \pm 0.6^{*}$ & $9.6 \pm 0.9$ \\
\hline \multicolumn{4}{|l|}{ Urine } \\
\hline Creatinine $(\mathrm{mg} / \mathrm{dL})$ & $29.5 \pm 13.3^{* *}$ & $50.4 \pm 32.5$ & $49.5 \pm 10.1$ \\
\hline Calcium (mg/dL) & $2.1 \pm 1.7$ & $5.9 \pm 4.6 \ddagger$ & $1.1 \pm 1.0$ \\
\hline
\end{tabular}

on the microscope. The images were analyzed using the Bioquant Osteo II (Bioquant Image Analysis Corp., Nashville, TN, USA) bone histomorphometry analysis program. The following parameters were identified: bone volume/total tissue volume (BV/TV), \%; mineralized volume/total tissue volume (MV/TV), \%; osteoid volume/bone volume (OV/BV), \%; osteoid volume/total tissue volume (OV/TV), \%; bone surface area/bone volume (BSA/BV), \%; bone surface area/total tissue volume (BSA/TV), \%; trabecular thickness (TbTh), $\mu \mathrm{m}$; trabecular number (TbN), mm; and intertrabecular space (TbSp), $\mu \mathrm{m}$.

\section{Statistical analysis}

Statistical analysis was performed using the SPSS version 15.0 software (SPSS Inc., Chicago, IL, USA). Descriptive data were expressed in mean and standard deviation (SD) with the range of values (min-max). Comparisons among the groups were applied using one-way ANOVA for normally distributed data and Kruskal-Wallis test for abnormally distributed data. The significant results were studied using the posthoc Bonferroni test with the assumption of a $\mathrm{p}$ value of 0.017 for each hypothesis. A $p$ value of $<0.05$ was considered statistically significant.

\section{RESULTS}

Significantly lower levels of plasma osteocalcin and plasma calcium were observed in the Ovx-PS group, compared to both Ovx-A and Shm groups. There was no significant difference in plasma creatinine levels among the groups. However, urine calcium levels were significantly higher in the Ovx-PS group, compared to the Ovx-A and Shm groups, while urine creatinine levels were significantly lower in the $\mathrm{Shm}$ group, compared to the Ovx-A group (Table 1).

The diameters of the tibial head and shaft are presented in Table 2. Both diameters significantly $(\mathrm{p}<0.05)$ decreased in the Ovx-PS group, compared to Shm and Ovx-A groups.

In addition, there are marked differences in the bone density of the tibial and vertebral bodies among the groups (Table 3). For the tibial measurement, the Ovx-PS group had a significantly $(\mathrm{p}<0.01)$ lower density than the Shm group, while it was significantly $(\mathrm{p}<0.01)$ higher in the Ovx-A group. Similar results were achieved for the vertebral body densities. There was no difference in the bone density between the tibial and vertebral bodies in the Shm and Ovx-PS groups, although the bone density was significantly $(\mathrm{p}<0.01)$ lower in the vertebral body, than the tibia in the Ovx-A group.

The results from biomechanical testing for the tibiae are presented in Table 4 . The median breaking force, the maximum applied force, and the force applied in the upward and downward direction showed a significant $(\mathrm{p}<0.05)$ decrease in the Ovx-PS group,

Table 2. Means, standard deviations, and range of diameters $(\mathrm{mm})$ of the tibial head and shaft according to experimental groups

\begin{tabular}{|c|c|c|c|c|c|c|}
\hline \multirow[t]{2}{*}{ Diameter } & \multicolumn{2}{|c|}{ Shm $(n=10)$} & \multicolumn{2}{|c|}{ Ovx-PS $(n=10)$} & \multicolumn{2}{|c|}{ Ovx-A $(n=10)$} \\
\hline & Mean \pm SD & Range & Mean \pm SD & Range & Mean \pm SD & Range \\
\hline Tibial head (mm) & $6.5 \pm 0.2$ & $6.27-6.95$ & $5.8 \pm 0.3^{*}$ & $5.30-6.10$ & $6.6 \pm 0.4$ & $6.14-7.30$ \\
\hline Tibial shaft (mm) & $4.1 \pm 0.3$ & $3.68-4.58$ & $3.8 \pm 0.2^{*}$ & $3.43-3.97$ & $4.5 \pm 0.5$ & $4.11-5.67$ \\
\hline
\end{tabular}


Table 3. Means, standard deviations, and range of densitometric values for the tibia and vertebral body according to experimental groups

\begin{tabular}{|c|c|c|c|c|c|c|}
\hline \multirow[t]{2}{*}{ Variable } & \multicolumn{2}{|c|}{ Shm $(n=20)$} & \multicolumn{2}{|c|}{ Ovx-PS $(n=20)$} & \multicolumn{2}{|c|}{ Ovx-A $(n=20)$} \\
\hline & Mean \pm SD & Range & Mean \pm SD & Range & Mean \pm SD & Range \\
\hline Tibia (mm/Al) & $87.0 \pm 6.4$ & $75.07-98.58$ & $67.0 \pm 4.3^{*}$ & $59.0-76.5$ & $114.3 \pm 6.3 \dagger$ & $102.43-124.00$ \\
\hline Vertebra $(\mathrm{mm} / \mathrm{Al})$ & $85.0 \pm 4.1$ & $78.97-92.69$ & $65.7 \pm 4.0^{*}$ & $57.3-71.2$ & $100.8 \pm 3.7 \dagger$, & $95.37-109.32$ \\
\hline
\end{tabular}

Shm: Sham; Ovx-PS: Ovariectomized-physiological saline; Ovx-A: Ovariectomized-alendronate; Al: Ölçüm alanı; ${ }^{\star} \mathrm{p}<0.01 ; \dagger \mathrm{p}<0.01 ; \ddagger \mathrm{p}<0.01$

Table 4. Range and median values $(\mathrm{N})$ of the breaking force, maximum applied force, force applied from below and from above for the tibia according to experimental groups

\begin{tabular}{|c|c|c|c|c|c|c|}
\hline \multirow[t]{2}{*}{ Variables } & \multicolumn{2}{|c|}{$\operatorname{Shm}(n=10)$} & \multicolumn{2}{|c|}{ Ovx-PS $(n=10)$} & \multicolumn{2}{|c|}{ Ovx-A $(n=10)$} \\
\hline & Min-Max & Median & Min-Max & Median & Min-Max & Median \\
\hline Breaking force $(\mathrm{N})$ & $0.80-10.16$ & 4.90 & $0.47-15.20$ & $3.44^{\star}$ & $0.75-12.05$ & $6.282 \dagger$ \\
\hline Maximum applied force $(\mathrm{N})$ & $18.64-28.93$ & 24.24 & $13,15-24.36$ & $18.48^{\star}$ & $11.97-26.67$ & $24.032 \dagger$ \\
\hline Force applied from below $(\mathrm{N})$ & $18.64-28.93$ & 22.66 & $6.44-16.64$ & $12.22^{*}$ & $0.00-25.99$ & $15.932 \dagger$ \\
\hline Force applied from above $(\mathrm{N})$ & $18.64-28.93$ & 21.56 & $4.25-24.36$ & $16.08^{*}$ & $11.97-26.67$ & $24.022 \dagger$ \\
\hline
\end{tabular}

Shm: Sham; Ovx-PS: Ovariectomized-physiological saline; Ovx-A: Ovariectomized-alendronate; Min: Minimum; Max: Maximum; ${ }^{*} \mathrm{p}<0.05 ; \dagger \mathrm{p}<0.01 ; \mathrm{N}:$ Newton.

compared to the Shm group. In addition, there was a significant $(\mathrm{p}<0.05)$ increase in these values in the Ovx-A group, compared to the Ovx-PS group.

Histological sections of the undecalcified femurs and vertebrae showed a normal trabecular structure in the Shm group (Figures 1,2). In contrast, there was an apparent deterioration in the Ovx-PS group (Figures 3, 4); however in the Ovx-A group, the histological sections showed a trabecular structure similar to the Shm group (Figures 5, 6).

The histomorphometric measurements for groups are shown in Table 5 for femurs and in Table 6 for vertebrae. For the femur, all histomorphometric measurements showed a significant $(\mathrm{p}<0.01)$ change in the Ovx-PS group, compared to the Shm group (Table 5).

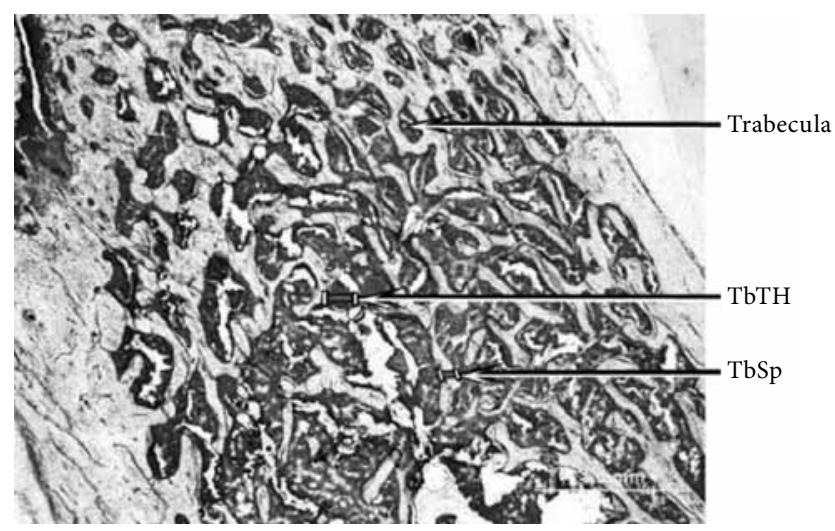

Figure 1. Undecalcified femoral section in Shm group: Toluidine blue (x40). Shm: Sham; TbTh: Trabecular thickness; TbSp: Intertrabecular space.
There was a decline in the BV/TV, MV/TV, OV/BV, OV/TV, BSA/TV, TbN, and TbTh and an increase in the $\mathrm{MV} / \mathrm{BV}, \mathrm{BSA} / \mathrm{BV}$, and TbSp. In contrast, in the Ovx-A, group there were significant $(\mathrm{p}<0.01)$ increases, compared to the Shm group, in all measurements, except for the BSA/BV and TbSp which both showed a significant $(\mathrm{p}<0.01)$ decline (Table 5). Accordingly, there were significant $(\mathrm{p}<0.01)$ differences in all histomorphometric measurements between the OvxPS and Ovx-A groups (Table 5), with all values being increased except for the BSA/BV and TbSp.

For the vertebrae, the histomorphometric findings were not as consistent as for the femurs (Table 6). Compared to the Shm group, there were significant $(\mathrm{p}<0.01)$ differences in the Ovx-PS group in all measurements: BV/TV, MV/BV $(\mathrm{p}<0.05)$,

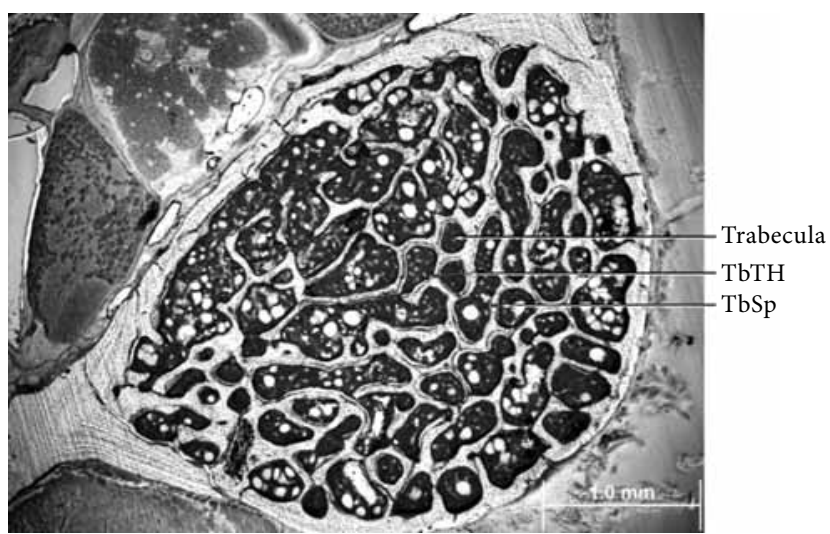

Figure 2. Undecalcified vertebral section in Shm group: Toluidine blue (x40). Shm: Sham; TbTh: Trabecular thickness; TbSp: Intertrabecular space. 


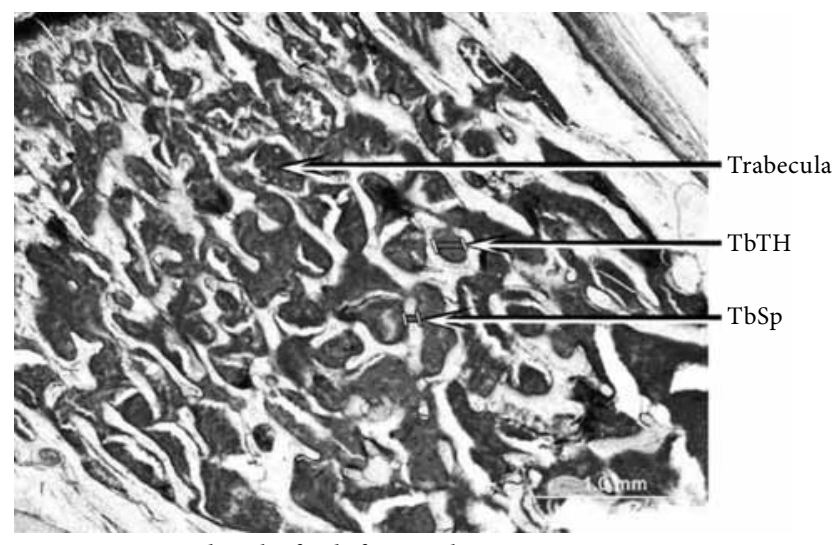

Figure 3. Undecalcified femoral section in Ovx-PS group: Toluidine blue (x40). Ovx-PS: Ovariectomized-physiological saline; TbTh: Trabecular thickness; TbSp: Intertrabecular space.

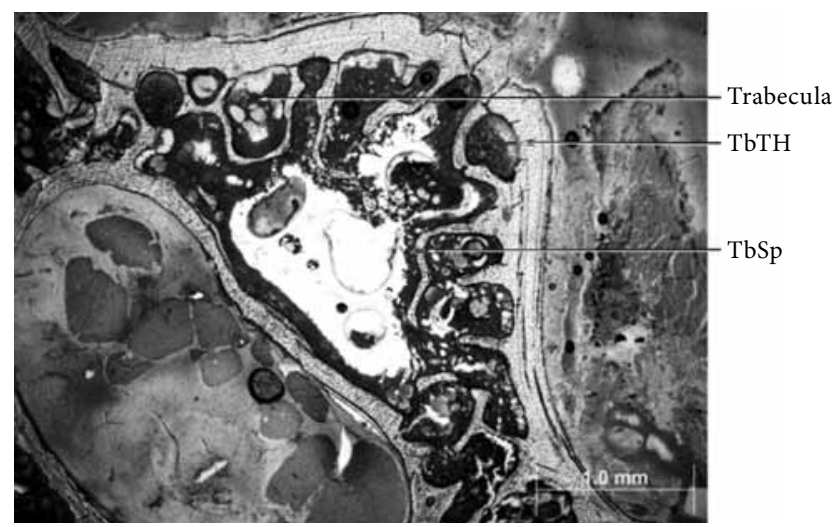

Figure 4. Undecalcified vertebral section in Ovx-PS group: Toluidine blue (x40). Ovx-PS: Ovariectomized-physiological saline; TbTh: Trabecular thickness; TbSp: Intertrabecular space.

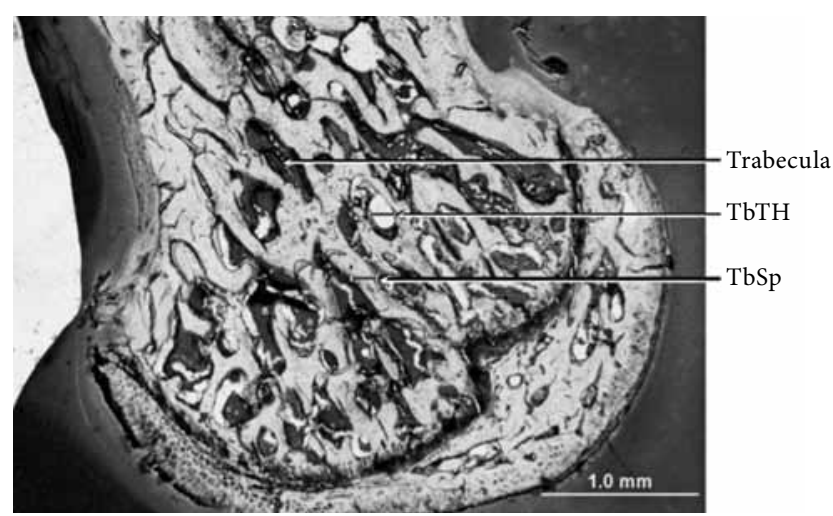

Figure 5. Undecalcified femoral section in Ovx-A group: Toluidine blue (x40). Ovx-A, ovariectomized-alendronate; TbTh: Trabecular thickness; TbSp: Intertrabecular space.

$\mathrm{MV} / \mathrm{TV}, \mathrm{OV} / \mathrm{BV}, \mathrm{OV} / \mathrm{TV}, \mathrm{BSA} / \mathrm{BV}$, and $\mathrm{TbN}$ all decreased $(p<0.01)$, while the BSA/BV, TbTh, and $\mathrm{TbSp}$ increased. Unlike to the femurs, there were less differences between the Ovx-A and Shm groups, which was limited to a significant $(\mathrm{p}<0.01)$ decline in the $\mathrm{TbN}$

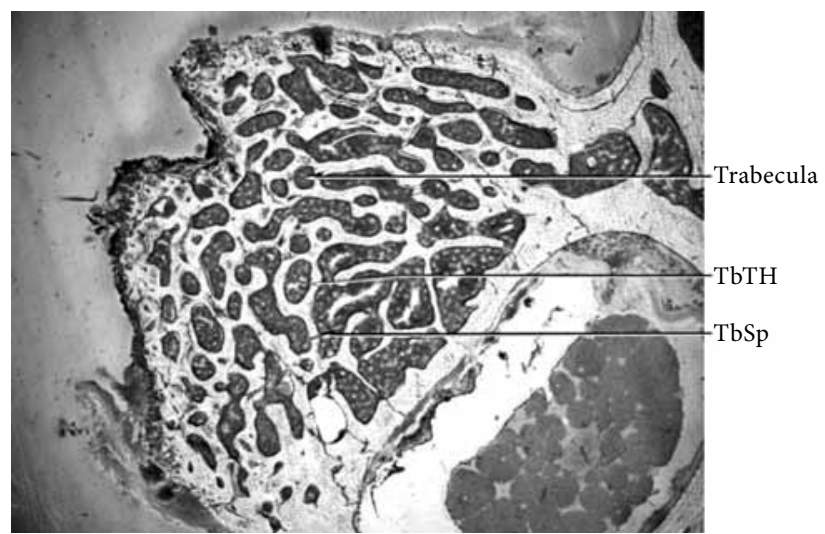

Figure 6. Undecalcified vertebral section in Ovx-A group: Toluidine blue (x40). TbTh: Trabecular thickness; TbSp: Intertrabecular space.

and TbSp and a significant $(\mathrm{p}<0.01)$ increase in the TbTh and BSA/BV $(\mathrm{p}<0.05)$. Compared to the Ovx-PS and Ovx-A groups, there were significant $(\mathrm{p}<0.01)$ differences in all histomorphometric measurements, all showing increases except for TbSp and BSA/BV in the Shm group $(\mathrm{p}<0.05)$.

\section{DISCUSSION}

Osteoporosis and related postmenopausal complications have an adverse impact on the quality of life in women. Due to increased life span and the use of more sophisticated diagnostic techniques. The high rate of bone loss in the Ovx rats has been shown to be preventable using similar postmenopausal treatment regimens as in humans ${ }^{[7-10]}$ As a result, the Ovx rat model is recognized as the gold standard in studies which aim to prevent and slow down osteoporosis in humans. In the present study, we developed an osteoporotic rat model to assess the effects of postmenopausal osteoporosis on trabecular bone formation. We used alendronate sodium as the pharmacological agent to reduce the loss of bone following ovariectomy. We observed highly significant positive effects of alendronate sodium on all parameters measured including plasma and urine biochemistry, bone morphometry, densitometry, and histomorphometry.

Elevated plasma osteocalcin levels following ovariectomy have been reported in previous studies ${ }^{[7-10]}$ A similar finding was observed in the present study in the Ovx group; however, the alendronate group showed no change in the plasma osteocalcin levels, compared to the Shm group. This finding supports the bone loss in the Ovx group without alendronate supplementation. 
Table 5. Histomorphometric analysis data for femurs

\begin{tabular}{|c|c|c|c|c|c|c|}
\hline \multirow[t]{2}{*}{ Variable } & \multicolumn{2}{|c|}{ Shm group $(n=20)$} & \multicolumn{2}{|c|}{ Ovx-PS group $(n=20)$} & \multicolumn{2}{|c|}{ Ovx-A group $(n=20)$} \\
\hline & Mean \pm SD & Range & Mean \pm SD & Range & Mean \pm SD & Range \\
\hline BV/TV (\%) & $34.8 \pm 3.4$ & $31.20-41.60$ & $13.9 \pm 1.8 \dagger$ & $11.40-17.30$ & $43.8 \pm 7.6^{*}, \ddagger$ & $28.00-69.50$ \\
\hline MV/BV (\%) & $92.0 \pm 9.0$ & $82.40-110.00$ & $118.0 \pm 15.5^{*}$ & $96.80-147.10$ & $177.3 \pm 25.1^{\star}, \ddagger$ & $122.80-254.70$ \\
\hline MV/TV (\%) & $27.5 \pm 2.7$ & $24.60-32.80$ & $12.0 \pm 1.6 \dagger$ & $9.80-15.00$ & $40.1 \pm 5.7^{\star} \ddagger$ & $28.80-59.80$ \\
\hline OV/BV (\%) & $14.9 \pm 1.5$ & $13.30-17.80$ & $9.0 \pm 1.2 \dagger$ & $7.30-11.20$ & $23.2 \pm 3.4^{\star}, \ddagger$ & $16.60-35.50$ \\
\hline OV/TV (\%) & $4.0 \pm 0.4$ & $3.60-4.80$ & $0.9 \pm 0.1 \dagger$ & $0.70-1.10$ & $5.7 \pm 0.9^{\star}$ & $4.00-9.00$ \\
\hline BSA/BV (\%) & $311.8 \pm 30.6$ & $279.30-372.90$ & $596.1 \pm 78.5^{\star}$ & $488.90-743.40$ & $193.3 \pm 26.9 \dagger, \S$ & $123.70-264.00$ \\
\hline BSA/TV (\%) & $84.3 \pm 8.3$ & $75.50-100.80$ & $55.9 \pm 7.7 \dagger$ & $45.80-70.00$ & $142.4 \pm 20.1^{\star}, \ddagger$ & $102.20-211.80$ \\
\hline $\mathrm{TbN}(\mathrm{n})$ & $9.4 \pm 0.9$ & $8.40-11.20$ & $6.1 \pm 0.8 \dagger$ & $5.00-7.60$ & $13.0 \pm 1.8^{\star}, \ddagger$ & $9.20-19.00$ \\
\hline $\operatorname{TbTh}(\mu \mathrm{m})$ & $46.0 \pm 4.5$ & $41.20-55.00$ & $27.4 \pm 3.6 \dagger$ & $22.50-34.10$ & $70.8 \pm 10.0^{\star}$,‡ & $50.90-105.50$ \\
\hline $\operatorname{TbSp}(\mu \mathrm{m})$ & $171.1 \pm 16.8$ & $153.30-204.70$ & $543.8 \pm 71.6^{*}$ & $446.00-678.20$ & $145.2 \pm 24.6 \dagger, \S$ & $87.10-239.70$ \\
\hline
\end{tabular}

Shm: Sham; Ovx-PS: Ovariectomized-physiological saline; Ovx-A: Ovariectomized-alendronate; BV/TV: Bone volume/total tissue volume; MV/BV: Mineralized volume/bone volume; MV/TV: Mineralized volume/total tissue volume; OV/BV: Osteoid volume/bone volume; OV/TV: Osteoid volume/total tissue volume; BSA/BV: Bone surface area/bone volume; BSA/TV: Bone surface area/total bone volume; TbN: Trabecular number; TbTh: Trabecular thickness; TbSp: Intertrabecular space; ${ }^{\star} \mathrm{p}<0.01 ; \dagger \mathrm{p}<0.01 ; \ddagger \mathrm{p}<0.01 ; \S \mathrm{p}<0.01$.

Similar positive effects of alendronate have been also reported in the literature..$^{[9-17]}$

In addition, plasma calcium levels decreased in the Ovx group, compared to the Shm and alendronate groups with no difference between the $\mathrm{Shm}$ and alendronate groups. Iwamoto et al. ${ }^{[14]}$ reported decreased plasma osteocalcin and urine deoxypyridinoline levels with increased plasma calcium levels in the Ovx rats. Earlier, Azuma et al. ${ }^{16}$ reported that plasma calcium levels decreased for 2 to 3 days after administration of a single dose of alendronate, but returned to normal values on Day 4. However, it is not possible to confirm these findings, as the plasma calcium levels were unable to be assessed until 57 days after ovariectomy and alendronate administration in our study.

Urine calcium and creatinine levels were analyzed using 24-hour urine samples taken immediately prior to sacrifice. Accordingly, creatinine levels significantly increased in the Ovx group supplemented with alendronate. A high standard deviation for the mean value in the unsupplemented Ovx group reflected that there was no difference, compared to the $\mathrm{Shm}$ group, despite the mean value being higher than in the alendronate supplemented group. Urine calcium was also observed to be significantly higher in the unsupplemented Ovx group. Contrary to Shiraishi et al., ${ }^{[17]}$ who reported a decline in the mean calcium/ creatinine ratio in the Ovx animals, there was a decrease in the alendronate supplemented group, but an increase in the unsupplemented group in our study. Previously, urinary calcium was reported to decrease with varying doses of bisphosphonates; however, this decline appears not to be dose-dependent. ${ }^{[16]}$ This can account for the differences between this study and that of Shiarishi et al. ${ }^{[17]}$ This loss of calcium is, nevertheless, important, as hypercalciuria is one of the most common features of postmenopausal bone loss with osteoporosis in $50 \%$ of patients. ${ }^{[18,19]}$

Table 6. Histomorphometric analysis data for vertebrae

\begin{tabular}{|c|c|c|c|c|c|c|}
\hline \multirow[t]{2}{*}{ Variable } & \multicolumn{2}{|c|}{ Shm group $(n=20)$} & \multicolumn{2}{|c|}{ Ovx-PS group $(n=20)$} & \multicolumn{2}{|c|}{ Ovx-A group $(n=20)$} \\
\hline & Mean \pm SD & Range & Mean \pm SD & Range & Mean \pm SD & Range \\
\hline BV/TV (\%) & $38.5 \pm 7.2$ & $32.00-50.20$ & $11.3 \pm 0.7^{\star *}$ & $10.20-12.60$ & $40.6 \pm 6.2 \S$ & $32.00-50.50$ \\
\hline MV/BV (\%) & $110.6 \pm 18.2$ & $91.70-144.00$ & $95.9 \pm 5.7 \ddagger$ & $86.50-107.00$ & $116.6 \pm 17.9 \S$ & $91.70-145.00$ \\
\hline MV/TV (\%) & $32.3 \pm 6.0$ & $26.80-42.00$ & $9.7 \pm 0.6^{* *}$ & $8.80-10.90$ & $34.0 \pm 5.2 \S$ & $26.80-42.30$ \\
\hline OV/BV (\%) & $22.0 \pm 3.2$ & $18.30-28.70$ & $7.3 \pm 0.4^{* *}$ & $6.60-8.10$ & $23.2 \pm 3.6 \$$ & $18.30-28.90$ \\
\hline OV/TV (\%) & $6.3 \pm 0.6$ & $5.20-8.10$ & $0.7 \pm 0.0^{* *}$ & $0.60-0.80$ & $6.6 \pm 1.0 \S$ & $5.19-8.21$ \\
\hline BSA/BV (\%) & $378.6 \pm 34.1$ & $303.50-200.40$ & $484.2 \pm 28.8^{\star}$ & $437.00-540.30$ & $430.2 \pm 66.0 \dagger, 9$ & $338.50-535.10$ \\
\hline BSA/TV (\%) & $113.7 \pm 27.6$ & $94.20-147.80$ & $45.4 \pm 2.7^{\star \star}$ & $41.00-50.60$ & $119.7 \pm 18.4 \S$ & $94.80-148.90$ \\
\hline $\mathrm{TbN}(\mathrm{n})$ & $56.8 \pm 8.4$ & $47.10-73.90$ & $4.9 \pm 0.3^{* *}$ & $4.50-5.50$ & $9.8 \pm 1.5^{* *}, \S$ & $7.70-12.20$ \\
\hline $\operatorname{TbTh}(\mu \mathrm{m})$ & $9.3 \pm 0.9$ & $7.70-12.10$ & $20.7 \pm 1.3^{\star}$ & $17.20-23.00$ & $59.8 \pm 9.2^{\star}$ & $47.10-74.40$ \\
\hline $\operatorname{TbSp}(\mu \mathrm{m})$ & $130.4 \pm 22.7$ & $100.10-180.90$ & $441.8 \pm 26.3^{*}$ & $398.70-492.90$ & $13.4 \pm 2.2^{\star \star}, \|$ & $10.10-19.00$ \\
\hline
\end{tabular}

Shm: Sham; Ovx-PS: Ovariectomized-physiological saline; Ovx-A: Ovariectomized-alendronate; BV/TV: Bone volume/total tissue volume; MV/BV: Mineralized volume/bone volume; MV/TV: Mineralized volume/total tissue volume; OV/BV: Osteoid volume/bone volume; OV/ TV: Osteoid volume/total tissue volume; BSA/BV: Bone surface area/bone volume; BSA/TV: Bone surface area/total bone volume; TbN: Trabecular number; TbTh: Trabecular thickness; TbSp: Intertrabecular space; ${ }^{*} \mathrm{p}<0.05 ;{ }^{*} \mathrm{p}<0.05 ; \dagger \mathrm{p}<0.05$; $\neq \mathrm{p}<0.05$; $\S \mathrm{p}<0.05 ; \| \mathrm{p}<0.05 ; \mathrm{p}<0.05$ 
As the name refers, bone mineral density is a measure of the mineral content of a bone or specific region of a bone and, therefore, it indicates a measure of strength of a bone. In the present study, the diameters of the tibial head and shaft were significantly reduced in the unsupplemented Ovx group. These regions also showed significantly reduced bone mineral content in this group, compared to the alendronate supplemented and $\mathrm{Shm}$ groups. Interestingly, the alendronate group had significantly increased bone density, compared to the Shm group, which suggests a clear indication of bone resorption in the Ovx group and the beneficial effects of alendronate administration. Similar findings have been also reported in the literature. ${ }^{[9,19-21]} \mathrm{A}$ reduction in the bone mineral density has been reported for the greater trochanter, shaft, and distal epiphysis of the femur in the Ovx rats, compared to the Shm group. ${ }^{[16]} \mathrm{In}$ addition, Giavaresi et al. ${ }^{[22]}$ reported that, in rats treated with alendronate sodium following ovariectomy, there was a $15 \%$ increase in the bone density in the femoral epiphysis, compared to the control group, and a $27 \%$ increase, compared to the Ovx unsupplemented group. Significant increases in the mid-shaft and proximal femur have been also reported. ${ }^{[23]}$ These latter authors also reported that alendronate sodium treatment increased the bone thickness, strengthening both the cortical and medullary regions of the femoral head.

Bone mineral density of the vertebrae in our study showed similar values as those for the tibia. However, while the densities of the tibiae and vertebrae were similar for the Shm and unsupplemented groups, those for the alendronate group were significantly different with the density of tibiae higher than vertebrae. These results, together with those of previous studies, ${ }^{[23-33]}$ indicate that alendronate sodium treatment prevents loss of bone mineral density in long bones, such as tibia and femur in rats. Furthermore, it has been also shown that with alendronate sodium treatment, the bone mineral density in L4 and L5 shows a long-term increase which continues even after the treatment is discontinued. ${ }^{[25-27]}$

In their study on Ovx rats, Fuchs et al. ${ }^{23}$ showed that alendronate sodium increased the bone strength as well as the diameter of the femoral shaft periosteum. They also reported an increase in femoral shaft strength, but not in the stiffness, which contrasts with the increased hardness of the femoral shaft reported by Azuma et al. ${ }^{[16]}$ In addition, there were positive effects on the L4 vertebra. It was also reported that alendronate sodium had no effect on the three-point bending test, but increased the maximal loading of femoral shaft, irrespective of the treatment dose. ${ }^{[16]}$ In another study, alendronate sodium and retinol significantly increased maximum load and breaking force of the femur in treated groups, compared to the Ovx animals not receiving treatment. ${ }^{[29]}$ The biomechanical tests in our study showed that the tibial breaking force, the maximum applied force, the forces applied from above and below all significantly decreased in the unsupplemented Ovx group, compared to the Shm group, but significantly increased in the alendronate supplemented group, compared to the Ovx group. The decline following ovariectomy supports the findings of previous findings; however the adverse effects of osteoporosis on bone appear to be alleviated with the use of alendronate, as clearly seen in the present and previous studies. It has been also reported that $\mathrm{BV} / \mathrm{TV}$, one of the histomorphometric measurements, is a strong predictor of the mechanical properties of bone. ${ }^{[33]}$ As this measure showed a significant decrease in the Ovx group, but not in the alendronate group, the micro-architecture of the bone in the Ovx unsupplemented group supports these biomechanical observations.

Furthermore, a decline in the bone turnover was reported in the Ovx rats treated with $17 \beta$-estradiol with the effect being more significant in the presence of alendronate sodium. ${ }^{[9]}$ These findings support the hypothesis that the changes in the bone tissue and its material properties are the direct results of altered bone turnover. In this study, significant differences were found in all histomorphometric measurements between the Shm and Ovx groups for the femur with the unsupplemented group, showing adverse changes and the alendronate group showing positive changes. There were also significant differences between the two Ovx groups. Although these changes were not observed for the vertebrae, the unsupplemented Ovx group showed adverse changes, compared to the Shm group. In addition, there were some differences between the alendronate supplement and Shm groups. For the femur, TbTh and TbN decreased, while the TbSp increased in the unsupplemented Ovx group, compared to the Shm group, suggesting a loss of trabecular bone followed by osteoporosis in the Ovx group. These findings are similar to those reported previously. ${ }^{[9,16]}$

In addition, the administration of alendronate increased trabecular bone formation and trabecular number and volume, which can support that alendronate sodium protects the micro-architecture of the trabecular bone in the Ovx animals. These findings are, again, similar to those reported in the distal femur by da Paz et al. ${ }^{[9]}$ with $17 \beta$-estradiol 
alendronate sodium administration in the proximal tibial metaphysis by Iwamoto et al. ${ }^{14}$ with alendronate sodium and alfacalcidol. Azuma et al. ${ }^{[16]}$ also reported an inhibition of bone loss caused by ovariectomy with alendronate administration, which can be attributed to the strong antiresorptive effect of alendronate sodium.

In the present study, histomorphometric measurements of vertebrae showed that the thickness, number and volume of the trabecula all decreased with a corresponding increase in the TbSp in the unsupplemented Ovx group, compared to the $\mathrm{Shm}$ group. We also found a decline in the amount of trabecular bone and the development of osteoporosis. These findings are consistent with those reported by Fox et al. ${ }^{[10]}$ In addition, Yao et al. ${ }^{[34-36]}$ and Hara et al. ${ }^{[37]}$ who examined L5, found that vertebral volume, trabecular number and trabecular and cortical bone thicknesses all decreased in the Ovx group, compared to the Ovx-A group. However, they found no significant differences in the vertebral bone volume or bone architecture in the Ovx rats receiving different doses of simvastatin, compared to a drug-free group and a Shm group. ${ }^{[36]}$ Despite these findings, Hara et al. ${ }^{[37]}$ showed that alendronate treatment in the Ovx rats improved the vertebral bone volume, trabecular and cortical thickness. In the present, we also showed an increase in the amount of trabecular bone with an increase in the $\mathrm{TbN}$ and trabecular volume and a decline in the TbSp. According to our findings and previous findings, the use of alendronate sodium or other bisphosphonates is an effective way of improving trabecular bone structure and protecting the biomechanical strength of bone in the Ovx rats.

This study was conducted with a single antiosteoporotic drug. The results cannot be generalized to all antiosteoporotic agents.

In conclusion, our study results suggest that alendronate sodium treatment in the Ovx rats inhibits osteopenia in the lumbar vertebrae, protects trabecular structure, strengthens the bone biomechanically, and, inhibits bone turnover, as evidenced by the biochemical markers.

\section{Declaration of conflicting interests}

The authors declared no conflicts of interest with respect to the authorship and/or publication of this article.

\section{Funding}

The authors received no financial support for the research and/or authorship of this article.

\section{REFERENCES}

1. Clinical practice guidelines for the diagnosis and management of osteoporosis. Scientific Advisory Board, Osteoporosis Society of Canada. CMAJ 1996;155:1113-33.

2. Pérez-López FR. Postmenopausal osteoporosis and alendronate. Maturitas 2004;48:179-92.

3. Grynpas MD, Lundon K. Bone quality in animal models of osteoporosis. Drug Development Research 2000;49:146-58.

4. Libouban H, Moreau MF, Legrand E, Audran M, Baslé MF, Chappard D. Comparison of histomorphometric descriptors of bone architecture with dual-energy X-ray absorptiometry for assessing bone loss in the orchidectomized rat. Osteoporos Int 2002;13:422-8.

5. Stepan JJ, Alenfeld F, Boivin G, Feyen JHM, Lakatos P. Mechanisms of action of antiresorptive therapies of postmenopausal osteoporosis. Endocrine Regulations 2003;37:227-40.

6. Rehman MT, Hoyland JA, Denton J, Freemont AJ. Histomorphometric classification of postmenopausal osteoporosis: implications for the management of osteoporosis. J Clin Pathol 1995;48:229-35.

7. Kharode YP, Sharp MC, Bodine PV. Utility of the ovariectomized rat as a model for human osteoporosis in drug discovery. Methods Mol Biol 2008;455:111-24.

8. Eastell R, Hannon RA. Biomarkers of bone health and osteoporosis risk. Proc Nutr Soc 2008;67:157-62.

9. da Paz LH, de Falco V, Teng NC, dos Reis LM, Pereira RM, Jorgetti V. Effect of 17beta-estradiol or alendronate on the bone densitometry, bone histomorphometry and bone metabolism of ovariectomized rats. Braz J Med Biol Res 2001;34:1015-22.

10. Fox J, Miller MA, Newman MK, Metcalfe AF, Turner CH, Recker RR, et al. Daily treatment of aged ovariectomized rats with human parathyroid hormone (1-84) for 12 months reverses bone loss and enhances trabecular and cortical bone strength. Calcif Tissue Int 2006;79:262-72.

11. Cao Y, Mori S, Mashiba T, Westmore MS, Ma L, Sato M, et al. Raloxifene, estrogen, and alendronate affect the processes of fracture repair differently in ovariectomized rats. J Bone Miner Res 2002;17:2237-46.

12. Ito $M$, Azuma $Y$, Takagi $H$, Kamimura $T$, Komoriya $K$, Ohta T, et al. Preventive effects of sequential treatment with alendronate and 1 alpha-hydroxyvitamin D3 on bone mass and strength in ovariectomized rats. Bone 2003;33:90-9.

13. Delmas PD, Schlemmer A, Gineyts E, Riis B, Christiansen C. Urinary excretion of pyridinoline crosslinks correlates with bone turnover measured on iliac crest biopsy in patients with vertebral osteoporosis. J Bone Miner Res 1991;6:639-44.

14. Iwamoto J, Seki A, Takeda T, Sato Y, Yamada H, Yeh JK. Comparative effects of alendronate and alfacalcidol on cancellous and cortical bone mass and bone mechanical properties in ovariectomized rats. Exp Anim 2006;55:357-67.

15. Sebba AI, Broy S, Kohles JD, Weissman P. Rapid suppression of bone resorption marker levels with ibandronate therapy in a bisphosphonate-naïve population. J Clin Densitom 2008;11:417-23. 
16. Azuma Y, Chokki M, Ohta T, Kiyoki M. Effects of alendronate on plasma calcium levels, urinary calcium excretion, and bone resorption markers in normal rats: comparison with elcatonin, synthetic eel calcitonin. Endocrinology 1996;137:2586-92.

17. Shiraishi A, Higashi S, Masaki T, Saito M, Ito M, Ikeda S, et al. A comparison of alfacalcidol and menatetrenone for the treatment of bone loss in an ovariectomized rat model of osteoporosis. Calcif Tissue Int 2002;71:69-79.

18. Giannini S, Nobile M, Dalle Carbonare L, Lodetti MG, Sella S, Vittadello G, et al. Hypercalciuria is a common and important finding in postmenopausal women with osteoporosis. Eur J Endocrinol 2003;149:209-13.

19. Gulam M, Thornton MM, Hodsman AB, Holdsworth DW. Bone mineral measurement of phalanges: comparison of radiographic absorptiometry and area dual X-ray absorptiometry. Radiology 2000;216:586-91.

20. Lane JM, Russell L, Khan SN. Osteoporosis. Clin Orthop Relat Res 2000;372:139-50.

21. Pastoureau P, Chomel A, Bonnet J. Specific evaluation of localized bone mass and bone loss in the rat using dual-energy X-ray absorptiometry subregional analysis. Osteoporos Int 1995;5:143-9.

22. Giavaresi G, Fini M, Gnudi S, Aldini NN, Rocca M, Carpi A, et al. Comparison of calcitonin, alendronate and fluorophosphate effects on ovariectomized rat bone. Biomed Pharmacother 2001;55:397-403.

23. Fuchs RK, Allen MR, Condon KW, Reinwald S, Miller LM, $\mathrm{McClenathan} \mathrm{D}$, et al. Strontium ranelate does not stimulate bone formation in ovariectomized rats. Osteoporos Int 2008;19:1331-41.

24. Hosking D, Adami S, Felsenberg D, Andia JC, Välimäki M, Benhamou L, et al. Comparison of change in bone resorption and bone mineral density with once-weekly alendronate and daily risedronate: a randomised, placebo-controlled study. Curr Med Res Opin 2003;19:383-94.

25. Fuchs RK, Phipps RJ, Burr DB. Recovery of trabecular and cortical bone turnover after discontinuation of risedronate and alendronate therapy in ovariectomized rats. J Bone Miner Res 2008;23:1689-97.

26. Li M, Jiao J, Meng XW, Xing XP, Xia WB, Zhou XY, et al. Effects of teriparatide and alendronate on bone mineral density of osteoporotic rats. Zhonghua Yi Xue Za Zhi 2005;85:335-8. [Abstract]

27. Nakamura Y, Hayashi K, Abu-Ali S, Naito M, Fotovati A. Effect of preoperative combined treatment with alendronate and calcitriol on fixation of hydroxyapatite-coated implants in ovariectomized rats. J Bone Joint Surg [Am] 2008;90:824-32.

28. Sliwiński L, Janiec W, Pytlik M, Folwarczna J, Kaczmarczyk-Sedlak I, Pytlik W, et al. Effect of administration of alendronate sodium and retinol on the mechanical properties of the femur in ovariectomized rats. Pol J Pharmacol 2004;56:817-24.

29. Kippo K, Hannuniemi R, Isaksson P, Laurén L, Osterman T, Peng Z, et al. Clodronate prevents osteopenia and loss of trabecular connectivity in estrogen-deficient rats. J Bone Miner Res 1998;13:287-96.

30. Mosekilde L, Thomsen JS, Mackey MS, Phipps RJ. Treatment with risedronate or alendronate prevents hindlimb immobilization-induced loss of bone density and strength in adult female rats. Bone 2000;27:639-45.

31. Nishida A, Ito M, Uetani M, Nakayama T, Tanaka T. Effect of etidronate on three-dimensional trabecular structure in ovariectomized or sciatic neurectomized rats. J Bone Miner Metab 2004;22:335-40.

32. Rico H, Gómez M, Revilla M, González-Riola J, Seco C, Hernández ER, et al. Effects of promethazine on bone mass and on bone remodeling in ovariectomized rats: A morphometric, densitometric, and histomorphometric experimental study. Calcif Tissue Int 1999;65:272-5.

33. Pothuaud L, Van Rietbergen B, Mosekilde L, Beuf O, Levitz P, Benhamou CL, et al. Combination of topological parameters and bone volume fraction better predicts the mechanical properties of trabecular bone. J Biomech 2002;35:1091-9.

34. Yao W, Hadi T, Jiang Y, Lotz J, Wronski TJ, Lane NE. Basic fibroblast growth factor improves trabecular bone connectivity and bone strength in the lumbar vertebral body of osteopenic rats. Osteoporos Int 2005;16:193947.

35. Yao W, Farmer R, Cooper R, Chmielewski PA, Tian XY, Setterberg RB, et al. Simvastatin did not prevent nor restore ovariectomy-induced bone loss in adult rats. J Musculoskelet Neuronal Interact 2006;6:277-83.

36. Yao W, Tian XY, Chen J, Setterberg RB, Lundy MW, Chmielzwski $\mathrm{P}$, et al. Rolipram, a phosphodiesterase 4 inhibitor, prevented cancellous and cortical bone loss by inhibiting endosteal bone resorption and maintaining the elevated periosteal bone formation in adult ovariectomized rats. J Musculoskelet Neuronal Interact 2007;7:119-30.

37. Hara K, Kobayashi M, Akiyama Y. Vitamin K2 (menatetrenone) inhibits bone loss induced by prednisolone partly through enhancement of bone formation in rats. Bone 2002;31:575-81. 